\title{
TEMPO E ESPAÇO: CONSIDERAÇÕES SOBRE O MODO DE VIDA DOS PESCADORES DO PARQUE NACIONAL DA LAGOA DO PEIXE - RS EM UM CONTEXTO DE CONFLITO AMBIENTAL. ${ }^{1}$
}

Gianpaolo K. Adomilli

O objetivo deste artigo é contribuir para o debate acerca da relação entre homem e natureza no que se refere à pesca artesanal. Considerando que a prática da pesca artesanal envolve uma relação singular para com o meio ambiente em termos ecológicos e simbólicos, a apropriação e representação do espaço realizada pelos pescadores são abordados enquanto aspectos centrais de sua organização social, vista como um referencial valorativo que implica noção de pertencimento ao lugar onde vivem e trabalham. Tal referencial baseia-se na relação com o meio natural e as condições de exploração da natureza. Nesse sentido, propõe-se fornecer, através de um estudo antropológico sobre o modo de vida dos pescadores do Parque Nacional da Lagoa do Peixe - RS, um enfoque centrado nas representações e práticas sociais relativas ao seu cotidiano de trabalho, com o objetivo de apresentar uma interpretação sobre as representações que estruturam suas ações coletivas. As práticas de trabalho, com características tradicionais, dizem respeito à detenção de um determinado saber sobre a natureza por parte destes pescadores, estetizando um ethos e compondo a visão de mundo do grupo. Assim, a relação com meio ambiente é caracterizada pela singularidade da prática de trabalho da pesca artesanal, sendo o produto fornecido pelo meio aquático. A singularidade refere-se à questão da tradição de uma pratica artesanal e do convívio de uma comunidade de pescadores vinculados a um território e ecologia específicos.

A pesca apresenta-se como elemento que preside a identidade social do grupo, pois exprime não apenas suas condições de existência, baseadas na sobrevivência por meio desta atividade, mas um modo de vida que engloba as demais esferas da vida social.

\footnotetext{
${ }^{1}$ Este artigo consiste em uma versão resumida, porém mais avançada, do Trabalho de Conclusão de Curso do autor orientado pela Profa. Dra. Cornelia Eckert, apresentado como requisição à obtenção de grau de Bacharel em Ciências Sociais (Dezembro de 2000), intitulado "Meio ambiente, conflito e identidade social: um estudo antropológico sobre os pescadores do Parque Nacional da lagoa do Peixe - RS".
} 
A temática do trabalho artesanal se dá em interface com estudos antropológicos sobre a questão ambiental, tendo em vista que estes pescadores estão inseridos em um espaço de preservação ecológica. Criado pelo decreto lei n. ${ }^{\circ}$ 93.546, o Parque Nacional da Lagoa do Peixe tem como objetivo a preservação de uma amostra representativa de um dos principais ecossistemas litorâneos do Brasil, sendo que há uma ênfase especial na proteção das aves migratórias. As aves vêm do hemisfério sul e do hemisfério norte e encontram local de descanso e alimentação na área do Parque. Pesquisadores de todo o mundo têm se interessado no estudo e proteção destas comunidades de aves, sendo a Lagoa do Peixe incluída na Rede Hemisférica de Reservas para Aves Limícolas, além do recente tombamento como parte da Reserva da Biosfera (reservas tombadas pela UNESCO). Juntamente com as aves, há uma fauna diversificada, como o camarão, peixes e mamíferos como a capivara e a lontra ${ }^{2}$.

$\mathrm{O}$ fato dos pescadores viverem e exercerem sua atividade dentro da área de preservação se apresenta em um contexto de tensão social, em decorrência do processo de implantação do Parque Nacional da Lagoa do Peixe, sobretudo no que se refere a políticas de gestão ambiental, mais precisamente, no que diz respeito a ecossistemas considerados ameaçados.

Consolidado nos Estados Unidos por volta do séc. XIX, o modelo de criação de Parques Nacionais baseia-se na proposta de criação de áreas isoladas da ação humana, para proteção ambiental (Diegues, 1996). A implantação deste modelo, pelo governo brasileiro, teve grande ênfase, principalmente a partir da década de 1970, durante o período de ditadura militar, resultando em uma série de conflitos com as comunidades locais que habitavam estas áreas. Estas comunidades foram consideradas, injustamente, como "agressores da natureza" e impossibilitadas de exercerem suas atividades ou expulsas das áreas de proteção. Mesmo com a instauração do quadro político-social de caráter democrático e liberal em que vive o país, iniciado na década de 1980, tais conflitos continuam atuais. No entanto, o quadro institucional democrático tem possibilitado uma maior organização política destas populações para lutarem por seus direitos.

\footnotetext{
${ }^{2}$ FNMA-FURG-IBAMA-NEMA-UFPEL. Plano de Manejo do Parque Nacional da Lagoa do Peixe - fase 2, 1999.
} 
Este quadro de problemática sócio-ambiental remete à necessidade de transcender à dualidade homem natureza, para um enfoque que integre a bio e a etnodiversidade ${ }^{3}$, no qual buscou-se resgatar as práticas socioculturais dos pescadores frente a um processo que tende à sua exclusão social, negando-lhes a identidade social e política. Trata-se de um contexto que diz respeito ao encontro entre duas óticas diferentes em relação à natureza. De um lado, os pescadores apresentam um conjunto específico de práticas sociais e simbólicas, que configuram entre si, a partir do ambiente em que vivem; e de outro, a política de Parques Nacionais, fundamentada em uma noção moderna de meio ambiente, representada por grupos urbano-industriais (principalmente pesquisadores, ecologistas e administradores). Esta noção está relacionada, entre outras coisas, à preocupação destes grupos com as consequiências do processo de degradação ambiental em nível mundial, inserindo-se em uma política relacionada à globalização, ou seja, uma política internacional sobre o meio, misturando um caráter instrumental de manutenção de ecossistemas considerados ameaçados, com uma visão romantizada acerca da natureza. Não se trata de voltar ao passado ou recuperar valores do passado, mas de uma lógica moderna de espacializar o mundo para construir nichos de "permanência", literalmente, para manutenção do ecossistema.

Considerando o processo de interação dos pescadores com a sociedade dominante, a ação do Estado, representado pelo IBAMA (Instituto Brasileiro do Meio Ambiente e Recursos Naturais Renováveis), que é o órgão federal que elabora e executa a política de gestão de parques e reservas, observa-se a existência de um contexto de injunções de mudanças, inseridas no âmbito das relações entre a cultura global e a diversidade cultural.

O grupo estudado forma uma comunidade pesqueira ${ }^{4}$, localizada na região que envolve a costa oceânica do Parque Nacional da Lagoa do Peixe ${ }^{5}$. Esta população se distribui nas praias do Lagamarzinho, Talha-mar e Farol. As praias do Lagamarzinho e Talhamar estão inseridas no espaço de preservação ecológica, enquanto que a praia do Farol situa-se em seus limites externos (portanto fora da área de preservação). Esses

\footnotetext{
${ }^{3}$ Sobre o assunto, ver Rocha (2000).

${ }^{4}$ Considera-se comunidade pesqueira de forma análoga ao conceito de comunidade de trabalho utilizado por Eckert (1993). A autora considera comunidade de trabalho no sentido de "grupo de identidade", dentro de um contexto que implica seu pertencimento social, enfatizando, entre outras coisas, as relações de reciprocidade e solidariedade.

${ }^{5}$ Entende-se por costa oceânica, a extensão do Parque Nacional da Lagoa do Peixe que se encontra exatamente na divisa com o oceano, onde estão as praias dos pescadores.
} 
grupos se deslocam, com freqüência, entre estas praias, apresentando laços de sociabilidade sedimentada em relações de trabalho e parentesco.

\section{A paisagem local}

O Parque Nacional da Lagoa do Peixe está localizado na península situada entre a Lagoa dos Patos e o Oceano Atlântico, na região que abrange os municípios de Tavares, Mostardas e uma parcela de São José do Norte. Com aproximadamente 34.400 hab., este território tornou-se Parque Nacional em 1986, constituindo-se em uma área essencial para preservação ecológica, principalmente de aves migratórias.

O território do Parque é formado pela Lagoa do Peixe e banhados. A lagoa é ligada ao oceano por uma barra, que costuma ser aberta por meio de uma escavadeira da prefeitura de Tavares, mas pode-se abrir, ou fechar, de acordo com os ventos e as marés, mantendo uma troca permanente entre lagoa e oceano. Quando a barra é aberta, as larvas do camarão-rosa entram do mar para a lagoa, onde se alimentam e crescem, constituindose em fonte de sustento dos pescadores locais, aproximadamente durante os meses de janeiro a maio. Durante os períodos de estiagem, a lagoa pode secar completamente, dependendo das condições do vento e das chuvas. A profundidade média varia de 10 a 60 centímetros, podendo chegar a 2 metros no inverno, quando ocorre o período de cheia e a água do mar adentra o continente. Terminado o período chuvoso, inicia-se um período lento e progressivo de secagem da lagoa.

Além da abertura da barra, pode-se observar a intervenção do homem moldando a paisagem na área que envolve os extremos da lagoa, onde a região apresenta uma faixa pantanosa em que se encontram cultivos de arroz. Na parte leste, há dunas e uma plantação de Pinus eliotis com aproximadamente $12 \mathrm{Km}$ de extensão ${ }^{6}$. No lado oeste da lagoa, encontra-se uma mata nativa, onde habitam pequenos produtores rurais ${ }^{7}$, sendo que entre esta mata e a lagoa, a região é pantanosa.

\footnotetext{
${ }^{6}$ O Pinus eliotis é uma espécie exótica, que foi introduzida na região na década de 1980. Percorrendo a BR101 entre Mostardas e Tavares, até a entrada do Parque, vêem-se extensas florestas de Pinus eliotis e algumas madeireiras. A terra é arrendada para a exploração destas florestas, sendo que boa parte da madeira é exportada.

7 Entre estes pequenos produtores, encontram-se aqueles que criam gado e outros que são pescadoresagricultores, predominando o cultivo da cebola. Segundo Maldonado, devido a complementaridade entre a pesca e a agricultura, os pescadores-agricultores "são considerados freqüentemente camponeses, talvez pelo fato de explorarem também a terra.” (Maldonado, 1986).
} 
Os pescadores que habitam o Parque Nacional da Lagoa do Peixe encontram-se ao longo da costa oceânica do Parque ${ }^{8}$, concentrando-se, em quase sua totalidade, em duas comunidades pesqueiras: uma delas é constituída pela vila da Barra, e a outra, objeto da pesquisa, constituída pelas praias do Talha-mar, Lagamarzinho e Farol. Ambas as comunidades são formadas por pescadores artesanais que ali residem, permanentemente ou durante determinados períodos de pesca. Por estarem dentro da área de preservação, a Barra, o Talha-mar e o Lagamarzinho dispõem de uma infra-estrutura precária. Não há luz elétrica, sendo utilizados lampiões a gás para iluminação das casas durante a noite. As moradias são barracos de madeira, construídos de forma simples, e a água utilizada é extraída de poços superficiais, cavados pelos próprios pescadores, provavelmente contaminados, pois se encontram muito próximos às latrinas. Já a praia do Farol, por localizar-se nos limites externos do Parque (portanto, fora da área de preservação), dispõe de energia elétrica e uma população maior de pescadores. Estes grupos vivem da pesca do camarão e de peixes, como tainha, pescadinha e papa-terra. Trata-se de uma pesca baseada em um saber tradicional que envolve, desde a confecção e o reparo de redes, até as técnicas específicas de pesca, baseadas em um determinado conhecimento das condições da natureza, como o mar e os ventos.

A atividade pesqueira divide-se em dois ciclos ecológico-econômicos, o "verão" e o "inverno". No ciclo do inverno, que ocorre aproximadamente de maio a dezembro, a atividade principal é a pesca na beira da costa de algumas espécies de peixes e do camarão sete-barbas. O ciclo do verão ocorre, aproximadamente, de janeiro a maio, quando se pesca o camarão-rosa na Lagoa do Peixe.

\section{Pescando vacas: um estudo comparativo entre etnografias sobre tempo e} espaço

O contexto ecológico no qual os pescadores estão inseridos implica uma relação entre tempo e espaço que pode ser observada de forma análoga ao enfoque dado pelos estudos clássicos de Evans-Pritchard (1978) sobre os Nuer, povo nilótico, cuja atividade principal diz respeito ao gado, um elemento fundamental para a compreensão de seu modo

\footnotetext{
${ }^{8}$ Os limites marinhos do Parque se iniciam próximo ao Farol de Mostardas, estendendo-se por $35 \mathrm{Km}$ ao sul e $1 \mathrm{Km}$ mar adentro.
} 
de vida. Em seu estudo desenvolvido junto aos Nuer, Evans-Pritchard abordou a ecologia daquele povo, constatando que

As limitações ecológicas e outras influenciam suas relações sociais, mas o valor atribuído às relações ecológicas é igualmente significativo para a compreensão do sistema social, que é um sistema dentro do sistema ecológico, parcialmente dependente deste e parcialmente existindo por direito próprio. Em última análise, a maioria - talvez todos dos conceitos de espaço e tempo são determinados pelo ambiente físico, mas os valores que eles encarnam constituem apenas uma das muitas possíveis respostas a este ambiente e dependem também de princípios estruturais, que pertencem a uma ordem diferente de realidade (Evans-Pritchard, 1978:107).

Neste sentido, a noção de espaço dos pescadores diz respeito a suas relações ecológicas, vinculadas ao território do Parque, sendo significativo para a definição do modo como se organiza sua vida social, observando-se a dependência da natureza e suas condições para a realização da pesca, assim como no que se refere aos deslocamentos entre a praia e a lagoa, dentro da divisão entre os ciclos de inverno e verão.

Há, nesta comunidade, duas categorias de tempo que obedecem a duas dimensões significantes acerca de acontecimentos que marcam os grupos ao nível da relação de eventos, constituindo-se de grande interesse para os pescadores. Evans-Pritchard (1978) as define como "tempo ecológico" e "tempo estrutural". A primeira diz respeito à relação com o meio ambiente, podendo ser observada na referência aos ciclos do verão e do inverno, dividindo-se o tempo de um ano em duas partes, onde o conceito de tempo relativo às estações está relacionado mais à dinâmica social que envolve os ciclos do que quanto à condição climática propriamente dita. A segunda refere-se aos fatos que marcaram "mudanças no relacionamento de grupos sociais", sendo que, na memória dos pescadores, tem-se referência a transformações como a implantação do Parque, a construção de estradas, e o surgimento e desaparecimento de vilas na costa oceânica do Parque.

Os aspectos que definem os ritmos da vida social são os ritmos da pesca (conforme veremos no próximo capítulo). Os deslocamentos, de acordo com os ciclos e com os períodos de escassez e fartura na pesca, envolvem toda a relação de socialização entre os pescadores, transformando o "ritmo ecológico" em "ritmo social" anual. Portanto, de 
acordo com esses ritmos, constata-se, em relação ao tempo, que sua duração se dá a partir da atividade pesqueira. Por um lado, há a noção de tempo concreto, no sentido do tempo perdido em uma pescaria frustrada (onde o período de pesca favorável deve ser bem aproveitado para garantir um certa renda e suprir as necessidades de subsistência), mas por outro lado, se apresenta um tempo sem esse caráter concreto, no sentido de que a variabilidade da prática pesqueira ocorre de acordo com a dependência em relação às condições da natureza. A noção de tempo também é definida por essas condições. De certo modo, o tempo está ligado às obrigações dos pescadores, às atividades rotineiras, ou seja, à atividade pesqueira. Estas obrigações apresentam um caráter econômico, sendo que, para Evans-Pritchard,

São as próprias atividades, notadamente as de tipo econômico, que constituem as bases do sistema e fornecem a maioria de suas unidades e notações, e a passagem do tempo é percebida na relação que uma atividade mantém com as outras (EvansPritchard, 1978:115).

Outro aspecto relevante diz respeito as proximidades e distanciamentos em relação aos grupos que habitam o Parque, definidas por Evans-Pritchard como "distância ecológica" e "distância estrutural":

O espaço ecológico é mais do que uma distância física, embora seja afetado por ela, pois também é calculado por meio do caráter da região que se situa entre grupos locais e por meio da relação dessa região com as exigências biológicas de seus membros. [...] a distância ecológica nesse sentido, é uma relação entre comunidades definida em termos de densidade e distribuição, e com referência a água, vegetação, vida animal e de insetos e assim por diante (Evans-Pritchard, 1978:122).

Assim, observa-se essa relação de distâncias nos ciclos do inverno e do verão para com a comunidade formada pelos pescadores do Lagamarzinho, Talha-mar e Farol em relação aos pescadores da Barra, onde as proximidades e distâncias entre os grupos são dadas de acordo com o "espaço ecológico". Diferentemente do que ocorre no ciclo do inverno, onde, como veremos, o espaço ocupado pelas comunidades estão circunscritos, basicamente, às vilas de pescadores e aos pontos de pesca ao longo das praias, no ciclo do verão, pescadores de diferentes localidades deslocam-se para as margens da lagoa, onde 
permanecem acampados por meses, situando-se no mesmo espaço. De acordo com o que Evans-Pritchard define como "distância estrutural” observa-se que, de certo modo, surgem alguns aspectos relativos às relações entre as comunidades de pescadores.

Constata-se, em relação ao ciclo do verão que, embora o espaço da lagoa seja comum aos pescadores de ambas as comunidades, formam-se pequenos agrupamentos somente entre os pescadores pertencentes à mesma comunidade. Portanto, não ocorre uma mistura entre os grupos, mas mantém-se uma "distância”, que é uma "distância estrutural". A "distância estrutural" refere-se a certas divisões entre as comunidades, principalmente, quanto ao nível do parentesco e de grupos políticos.

\section{Homens, camarões e cebolas: a história do grupo e do lugar}

De acordo com relatos dos pescadores mais velhos, tem-se referência de grupos que já habitavam a costa oceânica, hoje considerada como Parque Nacional da Lagoa do Peixe, por volta das décadas de 1940 e 1950. No entanto, eram três ou quatro famílias que viviam isoladas na extensão das praias. Naquela época, como é ainda hoje, a grande maioria da população que habitava a região consistia em famílias de agricultores, que se distribuíam na área que atualmente pertence ao município de Tavares ${ }^{9}$. Muitos deles se deslocavam em carroça da zona rural até as praias da costa oceânica e, principalmente, para a Lagoa do Peixe, a fim de complementar, com a pesca, os ganhos obtidos na agricultura.

Danilo, velho pescador do Talha-mar, elucida no relato de sua trajetória familiar, as condições de vida deste passado recente:

A nossa família era muito grande. Somo dezesseis filho. Nosso pai.. nos criou plantando cebola, mas os guri já tavam grande. Aí deixava os guri a trabalhá na cebola e pescava, ficava um mêis aqui na beira da lagoa. [...] Mesmo ali, naquela Véia Terra ali, com o falecido meu pai... nós parava embaixo dum carro, duma lona, que botava em cima do carro, e dormia embaixo. Salgava o peixe...era o camarão, era a tainha, era a traíra. Nós vendia ela em arroba, naquela época era em arroba. [...] o cara salgava o camarão, fervia o camarão. Aí o cara fervia e levava aqueles tachão grandão, fervia e salgava tudo e depois botava tudo na esteira. Aqueles peixe tudo que de primeiro nós pegava, nós botava nos arreio do cavalo e vinha de arrasto a cola do

\footnotetext{
${ }^{9}$ No início dos anos 1960 foi criado o município de Mostardas (Lei 4691 de 26/12/63), desmembrando-se do município de São José do Norte. O município de Tavares, surgiu no início da década de 1980 (Lei 7655 de 12/05/1982), desmembrando-se de Mostradas.
} 
peixe. $\mathrm{O}$ falecido meu pai cansava de vir aqui no mar pegá a Meraguaia, até na lagoa. Era de arpão. Ia de cavalo. Pegava mesmo de cavalo, de arpão. Pegava de arpão. Um baita dum peixe! O cara botava nos arreio do cavalo e o peixe ia de arrasto. E a tainha aqui na lagoa nós carregava de carreta. Boi, puxando a carreta. Levava o peixe e salgava. (Danilo)

Identifica-se um passado que reflete sobre as técnicas de trabalho e as espécies de peixes que eram pescados. Neste caso, salgar e secar ao sol o peixe e o camarão era a única forma de conservação, pois não havia energia elétrica para a produção de gelo. A atividade pesqueira dividia-se entre a captura do peixe e a salga. Os materiais de pesca também eram outros. Em relação aos tipos de peixes, hoje algumas espécies são consideradas praticamente extintas, como é o caso da miraguaia. Os Pescadores costumam a referir-se à esse peixe com nostalgia, remetendo à uma época de fartura em que havia uma abundância de peixes.

Naquele período, já havia uma população de agricultores-pescadores na região em geral, obedecendo a um calendário específico de atividades complementares, principalmente entre a cultura da cebola ${ }^{10}$ e a pesca do camarão-rosa e da tainha.

A partir da década de 1940, o processo de migração de pescadores catarinenses para a Lagoa dos Patos, a constituição da figura do intermediário e as inovações tecnológicas, como o aparecimento do motor, do gelo e novas técnicas materiais de pesca, levaram à intensificação desta atividade na região (Rodrigues Jr, Orlando \& Ruano, s/d). A pesca, na Lagoa do Peixe e na costa oceânica, não ficou isolada desde processo (embora tenha ocorrido mais tardiamente) sendo que, a partir dos anos 1960, a pesca do camarão-rosa na Lagoa do Peixe começou, progressivamente, a se consolidar como uma atividade que possibilitava rendimentos significativos, atraindo, além da população local, pescadores que viviam ao longo da costa litorânea do estado e, posteriormente, pescadores de Santa Catarina.

Em relação à população da região, constata-se que no meio rural o processo de migração de agricultores para outras regiões é um fenômeno que ocorre com certa freqüência, apresentando na maioria das vezes a questão da herança da terra ${ }^{11}$ ou perda da

\footnotetext{
${ }^{10}$ Tavares é considerada a "terra da cebola", sendo esta a principal atividade econômica da região. O cultivo de arroz e o corte de madeira (Pinus) também empregam uma parcela da população local.

${ }^{11}$ Há uma vasta literatura sobre a herança da terra nas famílias nucleares camponesas, tratado por diversos autores como, por exemplo, Bourdieu (1966), Wolf (1976), Queiroz (1972) e Woortmann (1995 e 1997),
} 
safra, como fatores determinantes. Neste caso, agricultores e pescadores-agricultores migraram para a costa oceânica da área do Parque, dedicando-se exclusivamente à pesca.

Paralelo ao crescimento da pesca na Lagoa do Peixe iniciou um processo de ocupação das praias da costa oceânica. As praias tornaram-se balneários e vilas de pescadores. As primeiras ocupações foram na Barra, considerada a vila de pescadores mais antiga. Depois surgiu a praia do Paiva, que começou a ser povoada por veranistas locais e alguns pescadores. Nas décadas seguintes, algumas outras praias foram surgindo ao lado do Paiva, como Lagamarzinho e Vinho. Nos anos 1980, ocorreram transformações significativas na região, como a emancipação do município de Tavares, a implantação de florestas de Pinus eliotis e a criação do Parque Nacional da Lagoa do Peixe. A formação do município de Tavares possivelmente levou a uma maior implementação de políticas públicas locais, como, por exemplo, se observa na abertura da estrada ligando o Talha-mar à RST-101, facilitando o acesso à costa oceânica.

A criação da estrada foi decisiva para o surgimento da praia do Talha-mar, que começou a ser povoada no início dos anos 1990. Nesse período iniciou-se um processo de deslocamento dos pescadores das praias do Paiva, Vinho e Lagamarzinho para o Talhamar, já que estas praias encontram-se em relativo isolamento, por não disporem da mesma facilidade de acesso proporcionada pela estrada. O Talha-mar é a praia mais recente da costa oceânica, tendo inicialmente atraído veranistas e pescadores locais. No entanto, por ter surgido após a criação do Parque, é considerada uma ocupação irregular pelo IBAMA que, por sua vez, tem projetos para reassentar pescadores e veranistas fora da área de preservação.

Além da estrada, outro motivo que levou ao esvaziamento do Paiva, Vinho e Lagamarzinho, pertence à ordem dos fenômenos naturais, como a ação erosiva das ressacas do mar sobre as casas. Os pescadores do Lagamarzinho contam que suas casas, que se situam entre a primeira e a segunda linha de casas em frente à praia, eram os "fundos" de uma vila, sendo que na beira da praia ainda se encontram escombros de algumas moradias e do que outrora foi um clube de moradores e veranistas.

apresentando, como pano de fundo, o problema da "falta de terra" para o crescente aumento da população camponesa. Conforme Wolf (1976), o processo de herança pode ser com ou sem a "partilha da terra", no entanto sempre implica migração de camponeses. 
Juntamente com o avanço do mar, houve também o avanço das dunas. Conforme relata a pescadora Neuza que, após ter morado boa parte de sua vida no Lagamarzinho, mudou-se para o Farol ao casar-se, mas manteve seu ponto de pesca e a casa no Lagamarzinho, até que o avanço das dunas acabou soterrando a casa:

Quando a gente morava lá [no Lagamarzinho] o combro já tava bem próximo, né. E aí, quando a gente saiu, a gente deixou a casa e a gente veio morá aqui [no Farol], mas a gente pescava lá né; parava lá quando ia pescá. Mas aí a areia tomô conta de tudo e... abandonamo tudo. E aí, a areia derrubô tudo mesmo, a gente não tiro nada, foi a areia mesmo que destruiu. (Neuza)

As representações sobre essas praias descrevem lugares em que a vida social era mais intensa, fazendo referência ao contato com pessoas "de fora", como veranistas, agricultores e pescadores de outras regiões, interessados no peixe e no camarão. Contudo, as praias do Vinho e do Paiva praticamente desapareceram, sendo visíveis apenas poucas casas abandonadas, escondidas entre as dunas, sendo visíveis os escombros, onde a figuração da ruína remete à morte da vida social que ali existiu. A natureza foi ocupando, novamente, os espaços das casas, que constituem o espaço simbólico que representa os grupos humanos, remetendo ao processo de não-intervenção do homem na natureza que procura ser implantado no local pelo IBAMA.

Apesar do abandono, essas praias continuam existindo para os pescadores, tanto por sua relação com o passado de um lugar em que muitos ali viveram, quanto no presente lugar de pescaria em que ainda se constitui, onde os referenciais de localização destas praias se dão pela demarcação dos pontos de pesca que alguns mantêm.

A comunidade se caracteriza por uma grande proximidade entre pescadores e agricultores, solidificada por laços de amizade e parentesco. Este contato pode resultar inclusive em relações de parentesco, como ocorre em boa parte dos casos através de casamentos endogâmicos ${ }^{12}$, ou seja, de agricultores que se casam com filhas de pescadores locais. Os casamentos endogâmicos também ocorrem em relação a pescadores de Santa Catarina que se deslocam sazonalmente para a Lagoa do Peixe. A ligação entre pescadores

\footnotetext{
12 Sobre o assunto, ver Eckert (1993). A autora define o termo "endogamia profissional" para casamentos dentro de uma "comunidade de trabalho", onde se conhecem e se formam as famílias, independente do nascimento ou não na comunidade.
} 
locais e catarinenses é considerável, sendo que os agricultores locais chamam os pescadores em geral de "catarinas".

A população das praias do Talha-mar e do Lagamarzinho é formada basicamente por filhos de pescadores que já habitavam a costa oceânica do Parque, somados a filhos de pescadores-agricultores que acabaram se dedicando, exclusivamente, à pesca e/ou aqueles que eram inicialmente ceboleiros e acabaram migrando para as localidades próximas, onde desempenhavam o trabalho de diaristas no plantio e colheita da cebola, passando a exercer a atividade pesqueira através do contato com os pescadores mais antigos.

Uma das explicações para a "mudança de profissão" diz respeito ao tipo de trabalho e à questão econômica relativa ao processo de desvalorização do preço da cebola nas últimas décadas, principalmente em decorrência da competição com a cebola produzida em outras regiões, aos gastos com agrotóxicos e os riscos de perda da safra.

Com a criação do Parque, o fluxo de pescadores de outros lugares diminuiu significativamente, pois o IBAMA fiscaliza a pesca do camarão-rosa, procurando controlar a permanência de pessoas na área de proteção, permitida somente aos pescadores que constam em seu cadastro e que são portadores de carteira de pescador profissional. Consequientemente, o fluxo de migrações foi reduzindo, levando ao isolamento as praias do Lagamarzinho e do Talha-mar. Outro aspecto relevante diz respeito às dificuldades enfrentadas pelos pescadores novos (geralmente filhos de pescadores locais) em obter a carteira de pescador profissional, que consiste em uma estratégia do IBAMA em diminuir, de forma progressiva, a atividade pesqueira na área de preservação. Desta forma, o nãoreconhecimento, por parte do IBAMA, destes pescadores novos influi diretamente na reprodução social da comunidade, levando a uma redução significativa da população de pescadores que ali viviam, sendo que a maior parte acabou se mudando para a praia do Farol, onde não há fiscalização.

No final da década de 1990, foi iniciado, pelo governo estadual, o asfaltamento da RST-101, conhecida até então como "estrada do inferno"13, demonstrando o estabelecimento progressivo de políticas públicas para a região. A abertura da estrada

\footnotetext{
${ }^{13}$ A "estrada do inferno", única rodovia de acesso à região, era uma estrada de areia que apresentava lamaçais e dunas ao longo de seu percurso, sendo que, com freqüência, veículos atolavam, justificando, portando, esse nome. Devido às suas péssimas condições, boa parte dos veículos transitava pela beira da praia, estabelecendo vias de ligação com a faixa litorânea do estado, principalmente com Tramandaí e Cidreira.
} 
que leva ao Talha-mar, o asfaltamento da RST-101 e a criação do Parque, acarretaram uma série de mudanças que constituem o cenário atual de contato dos pescadores do Parque Nacional da Lagoa do Peixe em geral, com a sociedade envolvente, demonstrando que, quando políticas públicas atuam sobre uma determinada localidade, tendem a causar impactos e regular as relações. Portanto, as mudanças ocorridas nos últimos 20 anos quanto à distribuição, concentração e esvaziamento dos pescadores ao longo da costa foram impulsionadas, principalmente, por dois fatores: a questão das vias de acesso, proporcionando uma maior facilidade de deslocamento, diminuindo as distâncias e conseqüentemente, o tempo das viagens, influenciando na concentração dos grupos locais; a criação do Parque, que resultou em um controle sobre a atividade pesqueira e a prática de estratégias que visam a retirada gradual dos pescadores da área de preservação, impedindo, por exemplo, a instalação de qualquer infra-estrutura nas vilas localizadas dentro da área de proteção.

\section{Pesca de rede}

As representações dos pescadores sobre seu modo de vida, centrado na atividade pesqueira, contempla a organização do trabalho, as relações sociais que se configuram neste universo e o saber sobre a natureza. Esta perspectiva implica perceber os elementos constituintes da organização social do grupo, baseados em práticas sociais concretas, em termos dos significados dados pelos próprios atores sociais, privilegiando-se, portanto, as interpretações que expressam sobre suas experiências vivenciadas a partir do cotidiano de trabalho.

A atividade pesqueira local se caracteriza pelo baixo emprego de tecnologia moderna, condição inerente à pesca artesanal quando comparada com a pesca industrial. Esta condição, somada à dependência em relação ao meio ambiente, constituí-se em um elemento fundamental sob o qual se efetivam as relações internas ao grupo.

Durante o ciclo do inverno, a atividade pesqueira ocorre na costa oceânica. A praia é demarcada pelos pontos de pesca, que consistem no espaço que o pescador dispõe para colocar suas redes. As redes de pesca ficam entre a segunda e a terceira rebentação das ondas, presas a um cabo que é amarrado a um toco de madeira cravado na areia. $\mathrm{Na}$ pescaria o cabo é puxado da beira da praia por alguma camionete ou jipe velho movido a 
gás de cozinha. São os veículos mais apropriados para o local, possibilitando o transitar na areia e nas estradas alagadas. Esses veículos geralmente apresentam ajustes na caçamba, ou mesmo em todo o chassi, feito de madeira, substituindo o original, já deteriorado ante a corrosão causada pela maresia. O gás de cozinha consiste na solução encontrada ante o custo da gasolina e da inexistência de postos de abastecimento no local.

Já a pesca realizada na lagoa consiste essencialmente na captura do camarão-rosa e apresenta o mesmo padrão de cultura material, porém um pouco mais simples do que aquele referente à pesca na beira da costa, sendo utilizados os seguintes artefatos básicos: caíques, redes (chamadas de "aviãozinho") e lampiões a gás.

Tanto na pesca da beira da costa, quanto na pesca da lagoa, a utilização do freezer se apresenta como solução ante a perecibilidade do produto, permitindo aos pescadores negociarem com o comprador. Torna-se possível esperar por um preço melhor, ou então, no caso de se ter pescado uma quantidade muito pequena de peixe ou camarão, insuficiente para que o comprador venha buscá-la, é possível manter a produção até que se acumule uma quantidade maior.

O freezer é almejado por muitos pescadores, mas sua utilização dentro da área do Parque torna-se inviável por falta de energia elétrica. Alguns pescadores utilizam geladeiras movidas a gás de cozinha, como solução provisória, que mesmo não apresentando a eficácia de um freezer, permite que o pescado seja conservado por algum tempo, além de possibilitar também a conservação de alguns mantimentos para o consumo familiar. Assim Gilberto, pescador que mora no Talha-mar, gela seu pescado no Farol. A alternativa encontrada por Gilberto, assim como por outros pescadores, baseia-se na rede de relações de reciprocidade do grupo, como nos esclarece sua fala, ao ser indagado como poderia gelar seu pescado se não tinha freezer:

É dos amigo, né. Mas isso aí... é amizade nossa, e se tivé... eu não tenho freezer, mas os amigo tem e eu vô lá, pergunto prá um: tem lugar? [...]. Se não tem lugar, arruma lugar, se não tem gelo, arruma gelo... devagarzinho a gente vai melhorando o preço, né.

Observa-se que, com ou sem freezer, os pescadores costumam dividir o peixe que não é vendido, sendo direcionado para a subsistência dos grupos de pesca, conforme as relações de reciprocidade presentes na vida social. Os grupos de pesca são, quase sempre, 
formados por dois ou três pescadores, organizados sob os sistemas de "meia" ou "terça". O pescador que é dono de ponto e possui rede, realiza uma parceria com outros pescadores, sendo que a divisão da produção pode ser em partes iguais ou não ${ }^{14}$.

A cooperação permeia toda atividade da pesca, configurando-se em um princípio fundamental que rege as relações entre os pescadores. Já a camaradagem, embora seja colada à cooperação, é explicitada em determinados momentos da atividade pesqueira, como na despesca, considerado como um trabalho muitas vezes cansativo, mas ao mesmo tempo como um momento de socialização, em que o grupo de pescadores conversa animadamente enquanto retira o pescado.

O grupo pode optar em realizar a pesca durante a noite. No caso da puxada à noite, $\mathrm{o}$ grupo se entretém através do jogo de cartas, mais especificamente, da "canastra", com o objetivo prático de permanecerem acordados. Este momento é de grande socialização, predominando a jocosidade; os pescadores conversam e dão risadas, contam piadas e bebem muito café, chimarrão e cachaça. O "carteado" e a "beberagem" não se restringem somente a esses momentos em que aguardam a puxada da rede, mas são típicas do convívio dos pescadores, embora seja durante o período em que estão pescando que esta socialização ocorra com maior intensidade, pois pequenos grupos de pescadores se agregam em torno da pesca.

Tanto a camaradagem quanto a cooperação relacionam-se com uma "troca de favores" entre os pescadores, constituindo-se em um aspecto fundamental para a coesão do grupo a partir da categoria "ajuda”, que, além do prisma da cooperação, adquire especial significado nos períodos de escassez, fortalecendo os laços sociais, uma vez que corre conforme os valores e comportamentos dos pescadores, de acordo com as relações de reciprocidade e parentesco existentes no grupo.

\section{O mar e a lagoa}

\footnotetext{
${ }^{14}$ De modo geral, se forem pescadores dispondo das mesmas condições (rede e ponto), chama-se "meia". Neste caso, o pescado é dividido em partes iguais. A "terça" costuma ocorrer quando um pescador é dono do ponto e da rede, trabalhando com um ou dois pescadores, que "entram com o corpo", recebendo, cada um, $20 \%$ do pescado. Ambos os sistemas de trabalho e divisão do pescado podem ainda apresentar outras variações, dependendo das condições de cada pescador que compõe o grupo de pesca. A relação de trabalho em que um pescador é dono do ponto e da rede, enquanto seu companheiro "entra com o corpo", apresenta determinada hierarquia. Um adquire o comando da atividade pesqueira frente ao outro, tomando todas as decisões, como, por exemplo, quando colocar e quando puxar a rede do mar.
} 
A pesca do camarão-rosa não requer a formação de grupos, como ocorre na beira da costa. O pescador não trabalha de forma coletiva, mas individualmente. Ocorre uma sociabilidade maior entre os pescadores, pois muitos permanecem acampados em volta da lagoa durante toda a temporada. Os acampamentos facilitam as relações de sociabilidade porque o convívio se dá em espaços mais próximos do que na beira da costa, pois não há uma demarcação territorial como se observa em relação aos pontos de pesca e ao espaço privado das casas. Portanto, se constata a existência de duas formas fundiárias: os acampamentos na lagoa, que caracterizam um "espaço comum”, e a beira da costa, onde os pontos de pesca constituem "espaços individuais". Esta diferenciação diz respeito a forma de trabalho desempenhada nestes locais, sendo que na beira da costa o trabalho é "coletivo" e o espaço "individual", enquanto que na lagoa ocorre o inverso. No entanto, estas formas são complementares, destacando-se a proeminência do coletivo sobre o individual em ambos os casos, pois indispensável à sobrevivência e coesão da comunidade.

A pesca na lagoa também favorece a constituição de um espaço onde muitos tomam iniciativas para a formação futura dos grupos de pesca na beira da costa. A articulação dos grupos geralmente ocorre com mais freqüência no "verão" porque é a partir deste período que se inicia o ano, sendo que no "inverno" o ideal é manter o mesmo grupo, ou seja, durante a temporada se mantém o grupo para então efetivar uma possível mudança de parceiros, para o próximo ciclo. Como se pode observar pela trajetória do grupo, este período também favorece a relação com pessoas de fora da comunidade, alguns dos quais acabam integrados ao grupo, seja por casamentos, seja pela relação de amizade que foi sendo construída.

No meio da tarde costuma-se preparar os lampiões a gás, para posteriormente colocá-los na lagoa. Consiste em "passar um gás”, ou seja, passar o gás de um bujão para os liquinhos dos lampiões, que também são revisados e desentupidos. Esta tarefa é diária e, ao entardecer colocam-se os lampiões com os "aviãozinhos" no caíque, remando até uma parte da lagoa, onde então os "aviãozinhos" são amarrados em estacas de bambu, que já se encontram cravadas na areia do fundo da lagoa. Na ponta das estacas são pendurados os lampiões, que ficam acesos durante toda a noite, atraindo com sua luz o camarão para dentro das redes. 
A permanência no local se justifica pelo ritmo de trabalho, pois os pescadores começam a entrar na água, por volta das 5h madrugada. Neste horário, um pouco antes do amanhecer, os "aviãozinhos" e os lampiões colocados ao entardecer do dia anterior, são retirados. Nas margens da lagoa realiza-se a despesca, onde o camarão é separado dos caranguejos $^{15}$. O camarão é colocado em caixas com capacidade de aproximadamente 25 quilos cada. Como ocorre na beira da costa, o comprador e os pescadores pesam as caixas, estipulando o valor a ser pago. No entanto, o pagamento não ocorre no ato, mas no fim da safra. Durante a safra, o pescador encomenda ao comprador, entre outras coisas, gás de cozinha, a substituição eventual de algum artefato de pesca danificado, como também a substituição de peças dos lampiões. Essas "encomendas" são descontadas do valor total da safra. Na pesca na beira da costa o processo de comercialização é praticamente o mesmo. A diferença é que, naquela, o pagamento ocorre antes do fim da safra, já que os rendimentos são menores e envolvem uma soma menor de dinheiro a ser paga pelo comprador.

De certo modo, comparando o ciclo do verão com o ciclo do inverno, observa-se que ambos são complementares, e a complementaridade ocorre de várias maneiras. Economicamente, o ciclo do verão é considerado mais produtivo, permitindo ao pescador uma renda maior em relação ao ciclo do inverno No caso do camarão-rosa, que chegou a valer $\mathrm{R} \$ 5,00$ o $\mathrm{kg}$ no verão de 2000, quando descascado tem o valor praticamente dobrado. Já o camarão sete-barbas, que no mesmo ano valia $\mathrm{R} \$ 5,00$ a caixa de $20 \mathrm{~kg}$, descascado valia $\mathrm{R} \$ 5,00 \mathrm{o} \mathrm{kg}$.

A diferença no preço do camarão evidencia a diferença entre os dois ciclos de pesca em termos econômicos. Soma-se a isto a questão da irregularidade da pesca, que ocorre com maior intensidade no ciclo do inverno, levando os pescadores à expectativa de que um eventual prejuízo no inverno possa ser reparado com uma boa safra no verão. A princípio, no caso de uma boa safra no verão, é possível saldar dívidas acumuladas no inverno.

Por outro lado, assim como a pesca no inverno, a safra do camarão-rosa também apresenta certa irregularidade, ambas dependendo das condições da natureza. Nos anos de

${ }^{15}$ Constatou-se a existência de duas espécies de caranguejo, sendo uma delas utilizada tanto para comercialização como para consumo do grupo. No entanto, o valor pago por sua captura é muito baixo se comparado com o valor do camarão-rosa, sendo preterido por este. 
forte estiagem, a lagoa quase fica seca, inviabilizando a pesca. Ou então, em um período muito chuvoso, pode-se alterar o nível de salinidade da lagoa, fazendo com que o camarão volte para o oceano.

\section{Útil para sobreviver, bom para pensar: o modelo de saber sobre a natureza}

A pesca da beira da costa se apresenta como oposta à pesca da lagoa no que diz respeito à instabilidade relativa aos ventos e às condições do meio aquático, exigindo do pescador um determinado saber sobre a natureza. Este saber baseia-se no conhecimento empírico para analisar constantemente as condições da natureza, a qual depende para desempenhar a atividade pesqueira. Sempre há conversas que avaliam as possibilidades de se colocar ou não uma rede no mar, partindo das observações baseadas neste saber. Apesar deste conhecimento, acumulado na experiência da pesca, as mudanças repentinas e as variações climáticas sempre ocorrem, levando o pescador a estar sempre alerta para evitar prejuízos. Como as variações são grandes em relação ao modelo ideal que será aqui apresentado, os "prognósticos" (Lima, 1996:121), enquanto "saber local ou tradicional", tem uma considerável influência de outras variáveis, como uma mudança brusca do vento, ou do mar. Inclusive, tanto os peixes como o camarão não permanecem em um lugar fixo, parados, mas movimentam-se constantemente, o que demonstra, mais uma vez, como a pesca envolve grande imprevisibilidade. Colocar a rede sempre implica "arriscar", não só no sentido de realizar uma boa pescaria, ou não, mas em uma eventual perda ou danificação dos artefatos de pesca.

Logo após um período de chuvas intensas, o "risco" consiste em colocar a rede no mar, pois pode ser retirada cheia de "lixo". O "lixo" vem com as cheias ocasionadas por chuvas constantes: juncos, plantas e galhos que são arrastados por córregos, rios e até mesmo banhados da região, desembocando no mar, e acabando por se prender às redes. A rede cheia de "lixo" permite que os peixes, ao visualizá-la, possam escapar. Somado a isso, os galhos e pedaços de madeira que se prendem à rede acabam por danificá-la, de tal modo que o pescador leva dias fazendo reparos. Segundo os pescadores, muitas vezes o "lixo" "viaja pelo mar", vindo de outras regiões, como no caso de um período de cheias no Taim/RS, em que grandes porções de junco vieram boiando dos banhados daquela região e foram parar ao longo da beira da costa. Para a surpresa dos pescadores, várias cobras, 
daqueles banhados, vieram juntamente com os galhos e juncos. Um dos pescadores contou, que em um dia, matou dez cobras na beira da praia, aproveitando-se que estavam "meio tontas com a água salgada". Este episódio permite observar que, mesmo sem chuvas no local, o "lixo" e algumas surpresas que podem acompanhá-lo, não se restringem apenas aos momentos chuvosos do local, mas também provêm de regiões próximas. No entanto, a chuva local é um parâmetro que oferece certa segurança aos pescadores. Entretanto, nem sempre há "lixo" após as chuvas, sendo que alguns arriscam colocar antes que os demais, enquanto que outros preferem aguardar, colocando, por exemplo, no dia seguinte. O pescador que colocou a rede antes do esperado pode realizar uma boa pescaria, mas não há garantias de sucesso, uma vez que também corre o risco de que pegar apenas "lixo".

Se colocar a rede exige uma ponderação das condições da natureza, também diz respeito à situação em que se encontra o pescador em termos de sua subsistência. Se o período é de escassez, como se presenciou em uma ocasião, durante o ciclo do inverno, a tendência é arriscar mais, embora, como foi demonstrado, quem arrisca pode fazer uma boa pescaria, mas também pode perder uma rede, o que significa um prejuízo considerável.

Para avaliação das condições de pesca, os ventos Nordeste e Sul são os que ocorrem com maior freqüência e interessam à pesca. Durante o ciclo do inverno, o vento Nordeste é considerado o mais importante, porque que costuma a "sujar" a água, ocasionando a combinação mais esperada e sendo o mais indicado para a pesca do camarão sete-barbas e da maioria dos peixes visados pelos pescadores da costa. Alguns dias contínuos, com a "força d'água" impulsionada na direção Nordeste, é a condição ideal para a pesca do crustáceo. A intensidade do vento e a "força d'água" são fundamentais.

No inverno, o vento Sul é associado às frentes frias e, quando é lua cheia, há grandes ressacas, inviabilizando a pesca. $\mathrm{O}$ grande interesse por este vento reside na ligação do mar com a lagoa, ou seja, ele empurra a água do mar para dentro da lagoa, ocasionando a mistura propícia para o camarão-rosa: a da água salgada do mar com a água doce das chuvas. Como a pesca do camarão-rosa se constitui no evento mais importante do ciclo ecológico anual dos pescadores, durante o período de pesca do "inverno", os prognósticos constantes em relação às condições da natureza não se resumem em ponderações sobre a 
safra do momento, mas tratam de acompanhar, constantemente, a dinâmica das condições da lagoa. A atenção dos pescadores em relação à lagoa ocorre mesmo quando não estão pescando naquele lugar.

A importância do vento, na vida dos pescadores, pode também ser constatada pela existência, em boa parte das casas, de duas portas de entrada, obedecendo a possíveis distribuições: uma fica na direção nordeste e a outra ao sul, ou então leste-oeste, ou ainda oeste-nordeste. Há sempre uma oposição, motivada pela mudança de vento no local, geralmente com certa intensidade. No entanto, é possível a ponderação sobre o vento dentro da própria casa, relacionando um espaço "interior" com um aspecto da natureza que é determinante na vida do pescador.

De certo modo, ao mesmo tempo em que é fonte de subsistência e meio de trabalho, o mar é representado por uma eterna "insegurança" em relação à pesca, pois é considerado instável, portanto, arriscado. Apesar dos prognósticos, as mudanças súbitas das condições climáticas e da correnteza refletem todo o quadro de imprevisibilidade na troca que o pescador tem com a natureza. As condições do mar são avaliadas quanto aos critérios de forte/fraco e claro/escuro, ou seja, quanto à intensidade da "força d'água" e sua noção de transparência da água, que pode ser "suja" ou "clara".

Outro aspecto em relação ao mar, diz respeito aos destroços de navios e produtos que acabam sendo encontrados na beira da praia. Tais destroços não são considerados "lixo", pois adquirem determinado valor. Alguns pescadores vasculham a praia recolhendo uma série de coisas, consideradas úteis, como bóias, garrafas, produtos de limpeza e até roupas e alimentos. Mário, por exemplo, conta, com satisfação, que certa vez comeu uma caixa de chocolates que encontrou intacta na beira da praia. Este pescador possui uma coleção de garrafas, todas encontradas na praia.

A mobilidade das espécies de peixes reforça a imprevisibilidade da pesca, tanto no mar como na lagoa. Há um movimento constante, com o deslocamento das espécies de acordo com as condições da natureza.

No caso do camarão, na lagoa, a combinação da mistura entre a água salgada do mar, que entra na lagoa pela barra, e as águas da chuva é que forma as condições propícias para sua reprodução, assim como de peixes. No entanto, o equilíbrio das condições naturais nem sempre ocorre. Dependendo do período, se houver uma seca prolongada, 
somado a um regime de ventos desfavorável, a água da lagoa pode ficar até mais salgada que a água do mar, impedindo que as larvas do camarão-rosa entrem na lagoa, o que pode ocorrer, igualmente, por excesso de chuvas. As restrições do IBAMA quanto à pesca do camarão visam proporcionar um período para que o crustáceo se desenvolva, evitando a pesca de espécimes ainda muito pequenos. Por outro lado, se para os pescadores há um reconhecimento de que esta medida visa proteger a espécie e, conseqüentemente, beneficiar a produção, muitas vezes se esbarra nas condições adversas propiciadas pela natureza, restando os esforços em pescar o camarão antes que saia da lagoa. Contudo, o IBAMA se mantém inflexível quanto à liberação das áreas de pesca, mesmo diante de circunstâncias adversas, tais como a grande estiagem ocorrida no verão de 2000, que ocasionou a morte precoce do camarão sem que os pescadores pudessem pescá-lo, gerando muita revolta e incentivando a pesca clandestina e predatória.

\section{A identidade de pequeno produtor}

A identidade de pequenos produtores adquire este sentido a partir da concepção de "liberdade" observada nas representações dos pescadores sobre seu trabalho, a pesca, ou seja, pescam visando a subsistência familiar, lidando com uma situação de imprevisibilidade constante, procurando proporcionar melhores condições para os filhos, assim como renovar os equipamentos de trabalho.

Em contraposição ao trabalho assalariado, estes "pequenos produtores" apresentam um sentimento de "liberdade", que vem entrelaçado à "responsabilidade" com que imprimem seu ritmo de trabalho, mantendo sua unidade doméstica, Desta forma, o pescador está em uma luta constante de sobrevivência e superação, onde a reprodução da unidade familiar também implica reprodução da condição de pequeno produtor, ou seja, trata-se de um duplo esforço de trabalho.

Se como dono dos seus meios de produção, o pescador tem, como representação de sua identidade, a condição de "liberdade", por outro lado esta se contrapõe a obrigatoriedade do ritmo do trabalho. Contudo, se a "liberdade" imprime um ritmo próprio de trabalho e o conhecimento da "arte de pescar", por outro lado é claramente limitada frente a necessidade de subsistência. Assim, a prática "independente" se depara com a imprevisibilidade da pesca e a do mercado, somada ao risco que os pescadores 
vivenciam de expropriação de suas condições de produção pela política governamental vigente, em um quadro de luta constante pela sobrevivência.

\section{“Quando a coisa arruina” na pesca}

Além da pesca do camarão-rosa, outro período de grande socialização dos pescadores é, justamente, aquele que coincide com a estagnação da pesca, pois é através da socialização que se fortalecem os laços sociais e se possibilita a obtenção de "ajuda" para enfrentar uma eventual falta de pescado.

Durante estes períodos, os pescadores costumam visitar os parentes e amigos. Embora entre os grupos de pesca o contato seja freqüente, e os pescadores passem boa parte do tempo uns nas casas dos outros, também ocorre, muito freqüentemente, deslocamentos para outras localidades, onde visitam parentes e reúnem-se com outros grupos. Em geral, os pescadores do Lagamarzinho e Talha-mar costumam deslocar-se para o Farol, mas também é comum irem a Tavares, onde alguns têm uma segunda casa e parentes que ali moram, permanecendo por alguns dias ou até que se retomem as atividades de pesca. Em Tavares, os pescadores compram alimentos, já que não existem supermercados ou armazéns dentro do Parque, e se encontram com outros grupos de pescadores e moradores da cidade em geral. O ponto de encontro é o bar "Metralha", localizado na área central, e que é freqüentado eminentemente por homens, pois se caracteriza por um espaço externo aos comunitários, onde confraternizam-se pescadores, agricultores e moradores do entorno.

Aqueles que, por um motivo ou outro, não se deslocam para Tavares ou para o Farol, se não têm que costurar uma rede, por exemplo, jogam snooker, chamado pelo grupo, de "taco". Somente os homens jogam "taco". Durante o inverno de 2000, acompanhou-se um grupo de pescadores que jogavam várias vezes ao dia. O jogo era realizado durante o dia em um bar abandonado no Talha-mar; a mesa, ligeiramente inclinada, não tirava o ânimo dos participantes, embora tivesse gerado protestos constantes quanto se errava a jogada, sendo que as justificativas sempre recaíam sobre o péssimo estado da mesa. A inexistência de luz elétrica fazia com que os pescadores jogassem apenas durante o dia e com as janelas abertas. 
O espaço público dos homens são os bares, onde bebem e jogam "taco". As mulheres, acompanhadas pelos maridos, vão eventualmente a festas que ocorrem, principalmente, em Tavares, comumente chamadas de "bailão" ou "domingueira".

Geralmente os amigos e parentes também visitam os pescadores, onde a troca se apresenta em seus diversos aspectos da vida social, como algo que é dado, e em contraposição, será retribuído em outra ocasião. Deste modo, a reciprocidade é vista aqui como elemento de coesão do grupo, e também de sobrevivência em um eventual período

de escassez. É freqüente a doação do peixe entre pescadores, assim como se visitarem e jantarem ou almoçarem uns nas casas dos outros. Assim como os amigos e parentes dos pescadores, vão até as vilas na costa oceânica e pescam junto com os pescadores ou carneiam um porco, da mesma forma os pescadores deslocam-se para Tavares ou para a zona rural, permanecendo ali durante certos períodos, mais curtos ou longos.

As práticas solidárias de lazer e parentesco dos pescadores para com os agricultores locais implicam certa medida no compartilhar de interesses em comum, relativo ao ethos configurador destes grupos sociais.

\section{A problemática ambiental e a questão da sobrevivência dos pescadores}

Os pescadores do Parque Nacional da Lagoa do Peixe apresentam um modo de vida constituído na relação com a natureza que pode ser observada pelos ritmos de tempo e pela estética de ocupação do espaço, dadas a partir de sua relação com o trabalho e inserção com o meio ambiente, recriadas nas relações sociais. A atividade pesqueira, de onde tiram seu sustento, fundamenta-se em um conhecimento singular em relação à natureza e aos ciclos naturais, cujas estratégias de utilização se valem os pescadores.

A política de gestão ambiental colocada em prática, na área de preservação, e suas estratégias de intervenção sobre os pescadores apontam para um processo de extinção do modo de vida desses grupos e de sua relação com o meio ambiente, mediante suas práticas culturais específicas, ou seja, de todo o seu processo ecossistêmico. De acordo com esta problemática, a situação dos pescadores do Talha-mar e do Lagamarzinho demonstra como essa forma de intervenção altera ambos os grupos, que vivenciam o isolamento, as restrições de suas atividades e o drama de uma possível desapropriação. 
O desmembramento da comunidade de trabalho e o relativo isolamento criam dificuldades para os pescadores, tendo em vista que as relações de reciprocidade ocorrem entre os pescadores e também em relação a parentes e amigos que, muitas vezes são impedidos de permanecerem no Parque

A reprodução da força de trabalho ocorre com dificuldades, praticamente não havendo renovação dos grupos. Como a determinação do IBAMA é restringir, ao máximo, a ação humana no Parque, o fluxo de pessoas que antigamente se integraram à pesca praticamente não ocorre mais, como, por exemplo, é o caso dos agricultores locais que trabalham como diaristas no plantio da cebola e que foram se incorporando aos grupos de pesca através do sistema de terças, adquirindo posteriormente seus pontos e redes, ou dos pescadores de outras regiões, que acabaram permanecendo e constituindo famílias.

Enquanto anteriormente os pescadores mais antigos aprendiam com os pais, atualmente os filhos dos pescadores, que ainda são menores de idade, não acompanham os pais nas pescarias com a frequiência esperada, devido ao Estatuto do Menor e do Adolescente. Outro aspecto importante é a escola. Como os pescadores têm um futuro incerto, querem proporcionar a seus filhos um grau de escolaridade mínima para que consigam empregos nas cidades.

A impossibilidade de haver qualquer infra-estrutura dentro do Parque e o plano de remover os pescadores que lá habitam, não permite, por exemplo, a existência de escolas nas localidades. Segundo os relatos dos pescadores, no Lagamarzinho havia uma escola, possibilitando que as crianças conciliassem os estudos com a atividade pesqueira. Contudo, durante a pesquisa, constatou-se que as escolas mais próximas localizam-se na vila do Farol e em Tavares, exigindo um deslocamento diário.

A escola, em si, praticamente inviabiliza a participação de crianças na pesca no ciclo do inverno. Já em relação ao ciclo do verão, a dificuldade se dá mais quanto à distância da escola em relação à lagoa e às vilas de pescadores, pois boa parte deste período de pesca coincide com as férias escolares. Desta forma, muitos filhos dos pescadores desvinculamse do meio dos pais e, futuramente, ao ingressarem na vida adulta, buscam outras atividades, muitas vezes migrando para outras regiões, onde trabalham como motoristas de caminhão, como operários em empresas, ou na construção civil. 
Assim a questão do conflito é tratada, em termos mais abrangentes, na relação de uma política global sobre o meio ambiente que, em última análise, faz parte de processos civilizatórios da sociedade complexa moderno-contemporânea. Tais processos têm avançado durante as últimas décadas na região, como se pode constatar, por exemplo, no que se refere a escolarização dos filhos dos pescadores e a tentativa de controlar o trabalho infantil, assim como as relações de mercado, que se dão através da comercialização do pescado, e os inserem numa realidade de mercado econômico mais global.

Em relação à ação específica do Estado, representado, na região, pelo IBAMA, demonstra-se que a interação com os pescadores se dá no sentido do exercício de um determinado controle e regulação da atividade pesqueira, incidindo diretamente na vida social do grupo.

Partindo do acompanhamento do cotidiano de trabalho dos pescadores, observou-se as relações de sociabilidade e reciprocidade, de acordo com os ritmos da vida social. Tais ritmos se dão a partir do trabalho e das relações com a natureza, recriadas nas relações sociais, onde o caráter itinerante do grupo é observado nos deslocamentos no tempo e espaço. Os pescadores, em suas práticas cotidianas, vivem da pesca, definindo o tempo de acordo com as principais safras de peixes e camarão, portanto, com o tempo ecológico, divido nos ciclos de inverno e verão. Mas o tempo também se relaciona com as condições de mercado, com o interesse dos compradores, sendo determinado por questões econômicas e políticas. A atividade pesqueira caracteriza-se por sua sazonalidade, pela dependência da natureza, o que implica pouco controle do pescador sobre os fenômenos da natureza no que tange ao tempo da pesca, aos ventos, as chuvas e a correnteza das águas. A relevância das condições da natureza que atuam na atividade pesqueira e que constituem o espaço litorâneo, mesmo que não sejam completamente determinantes, formam um conjunto de processos que influenciam as relações entre homem e natureza, particularizando as formas de apropriação humana. Neste sentido, se procurou levar em conta a relação com a natureza, com base no saber tradicional do grupo, destacando-se as representações sobre o meio em que vivem, observados na referência às condições para realização da pesca, como o saber sobre os ventos e as condições mar.

Outro aspecto a ressaltar, refere-se aos meios de trabalho, que definem o pescador como pequeno produtor, baseado no saber-fazer, que é interpretado como detendo valores 
da tradição e experiências passados geracionalmente. As diferenciações que podem ser estabelecidas na relação de trabalho entre os proprietários ou donos dos meios de produção e os não-proprietários, que "entram com o corpo" como força de trabalho, são absorvidas pelas relações de cooperação e camaradagem, caracterizando relações horizontais entre os pescadores, diferentemente das relações com o comprador, que é verticalizada e reflete uma dominação política e econômica.

A questão da identidade da comunidade de trabalho e como se organiza a vida social dos pescadores pode ser considerada a partir de três temas principais, de forma análoga à questão da construção da identidade social, trabalhada por Dias Duarte (In: Leite Lopes, 1987), em seus estudos sobre os pescadores do bairro de Jurujuba- Niterói (Duarte, 1978), levando em conta que, naquele caso, conforme coloca o autor, três aspectos fundamentais presidem a constituição da identidade social daqueles pescadores: os temas da "tradição", da "segregação" e da "decadência".

Apoiando-se neste autor temos a "segregação", que diz respeito ao isolamento geográfico da comunidade, aqui tratado em relação ao Parque Nacional da Lagoa do Peixe, onde os pescadores vivem em vilas isoladas por vários quilômetros de área de proteção ambiental. "Tradição" refere-se às praticas tradicionais, girando em torno da atividade pesqueira, passadas, na maior parte dos casos, geracionalmente. Este tema associa-se ao tema da decadência, no sentido em que este acentua certos aspectos de impedimento da reprodução social. Também apresenta a idéia de morte da comunidade, no sentido de um passado de fartura e vida social intensa, frente a um presente mais suscetível a transformações. O tema da "decadência" nos remete à questão do trabalho, no sentido de sua reprodução social ameaçada.

Um último aspecto a considerar, refere-se à limiaridade que caracteriza o grupo, que apresenta uma "passagem", ou transição, entre agricultores, ou pescadores-agricultores, e pescadores, caracterizando fronteiras muitas vezes tênues, como é a fronteira entre o mar e a terra, representada pela praia, e que caracteriza a vida anfíbia que levam os pescadores. É nesta fronteira tênue, de situação de limiaridade, que se constitui a identidade social do grupo, que apresenta estratégias de legitimação e afirmação de suas práticas tradicionais frente a processos de injunções de mudança. 


\section{REFERÊNCIAS}

ADOMILLI, G. K. Meio ambiente, conflito e identidade social: um estudo antropológico sobre os pescadores do Parque Nacional da lagoa do Peixe - RS. Trabalho de Conclusão de Curso, apresentado como requisição à obtenção de grau de Bacharel em Ciências Sociais UFRGS -Dezembro de 2000.

DIEGUES, Antonio Carlos, NOGARA, P. O nosso lugar virou parque: estudo sócioambiental do Saco de Mamangua-Parati- Rio de Janeiro. São Paulo: NUPAB-USP, 1994.

DIEGUES, Antônio Carlos. O Mito da Natureza Intocada. São Paulo, Hucitec, 1996.

DUARTE, Luiz Fernando Dias. As redes do suor. Niterói, Editora UFF, 1978.

ECKERT, Cornelia. Os homens da mina: um estudo das condições de vida e representações dos mineiros de carvão em Charqueadas/RS. Dissertação de mestrado em Antropologia Social. Porto Alegre, UFRGS, 1985.

ECKERT, Cornelia.. Ritmos e ressonâncias da duração de uma comunidade de trabalho: mineiros do carvão (La Grand-Combe, França). CADERNOS DE ANTROPOLOGIA. Memória e Identidade. UFRGS; PPGAS, N.11, 1993.

EVANS-PRITCHARD, E. E. Os Nuer. São Paulo, Perspectiva, 1993.

FNMA-FURG-IBAMA-NEMA-UFPEL. Plano de Manejo do Parque Nacional da Lagoa do Peixe - Fase 2. Serviço Público Federal, Ministério da Educação e do Desporto, Fundação Universidade do Rio Grande, 1999.

GEERTZ, Clifford. A interpretação das culturas. Rio de janeiro, LTC, 1999a.

GEERTZ, Clifford. $O$ saber local: novos ensaios em antropologia interpretativa. Petrópolis, Ed. Vozes, 1999b.

HALBWACHS, Maurice. Memória coletiva. São Paulo, Vértice, 1990.

LÉVI-STRAUSS, Claude. As estruturas elementares do parentesco. Petrópolis, RJ, Ed. Vozes, 1976.

LIMA, Roberto Kant de. Pescadores de Itaipu: Meio ambiente, conflito e ritual nolitoral do Estado do Rio de Janeiro. Niterói, EUFF, 1996.

LOPES, José Sérgio Leite. O vapor do diabo. Rio de Janeiro: Paz e Terra, 1978.

LOPES, José Sérgio Leite.. (Org) Cultura e identidade operária. Rio de Janeiro, Marco Zero, 1987.

MALDONADO, Simone Carneiro. Pescadores do mar. São Paulo, Ática, 1986.

MAUSS, Marcel. Sociologia e antropologia. Vol. II, São Paulo, EDUSP, 1974.

MAUSS, Marcel.. Ensaios de sociologia. São Paulo, perspectiva, 1981.

QUEIROZ, Maria Isaura de Pereira. O campesinato brasileiro. Petrópolis, ed. Vozes, 1972.

ROCHA, Ana Luiza Carvalho. Nas trilhas de uma bioetnodiversidade: a questão do olhar do outro e seus desdobramentos na construção dialógica das ciências ambientais. Instituto Antropos, Porto Alegre, 2000.

RODRIGUES J R, G. A atividade pesqueira no estuário da lagoa dos Patos, sua organização e transformação (nota prévia-mimeo). Rio Grande, 1988.

RODRIGUES JR, G., ORLANDO, A. M. \& RUANO DA SILVA, J. C. Evolução da atividade pesqueira na região estuarina da lagoa dos Patos - Projeto Lagoa dos Patos CIRM, s/d.

SAHLINS, Marshall. Cultura e razão prática. Rio de janeiro, Zahar Editores, 1972.

VELHO, Gilberto. Individualismo e Cultura: Notas para uma antropologia da sociedade contemporânea. Rio de janeiro, Jorge Zahar Editor, 1999.

WOLF, Eric. R. Sociedades camponesas. Rio de janeiro, Zahar Editores, 1976. 
WOORTMANN, Ellen. O trabalho da terra: a lógica simbólica da lavoura camponesa. Brasília, Editora UNB, 1997.

WOORTMANN, Ellen.. Herdeiros, parentes e compadres. Colonos do sul e sitiantes do nordeste. São Paulo - Brasília, Hucitec - Edund, 1995. 